\title{
Impact of size and shape of fresh-cut fruit on the drying time and fruit quality
}

Thijs Defraeye ${ }^{a, b} *$

${ }^{a}$ Multiscale Studies in Building Physics, Empa, Überlandstrasse 129, 8600 Dübendorf, Switzerland

${ }^{b}$ Chair of Building Physics, ETH Zurich, Stefano-Franscini-Platz 5, 8093 Zürich, Switzerland

\section{* Corresponding author}

- E-mail thijs.defraeye@empa.ch

- Tel. $\quad+41(0) 587654790$

- Fax. $\quad+41446331041$

Keywords: apple; convective; food; hygrothermal; modelling; COMSOL

\section{Abstract}

Insights are provided on how fruit size and shape affect the drying time and fruit quality loss, by simulating the convective drying process for cubic, rectangular, circular and half-circular fruit slices. Combined hygrothermal-quality modelling of the drying process unveiled, quantitatively, to which extent smaller samples dry faster and retain their quality better. For rectangular pieces with a large aspect ratio, so called fruit sticks, the drying time did not change anymore for increasing length. The compactness is proposed as a parameter to compare the drying process of fruits with different sizes and shapes with one another. The compactness is the ratio of the fruit volume to the surface area exposed to the environment. A good correlation function was found of both drying time and quality loss with the fruit compactness, where fruit with a lower compactness clearly dry faster. Such correlations can aid in estimating a-priori the drying time for a fruit of a certain size and shape.

This document is the accepted manuscript version of the following article:

Defraeye, T. (2017). Impact of size and shape of fresh-cut fruit on the drying time and fruit quality. Journal of Food Engineering, 210, 35-41. http://doi.org/10.1016/j.jfoodeng.2017.04.004

This manuscript version is made available under the CC-BY-NC-ND 4.0 license http://creativecommons.org/licenses/by-nc-nd/4.0/ 


\section{Introduction}

The duration of the drying process of fruits and vegetables is determined to a large extent by their size (Mujumdar, 2014). Smaller pieces take much less time to dry than large ones, due to the lower amount of moisture and the shorter pathway for moisture to be transported to the surface. A specific amount of fresh-cut fruit can be brought faster to a safe residual moisture content when it is cut up into small pieces, due to the larger total surface area for mass transfer, compared to larger pieces. Although the same amount of energy is needed to remove water from both batches, the reduced residence time in the dryer for smaller pieces can reduce operational costs and energy losses to the environment. The shorter drying time can also improve fruit quality as heat-sensitive compounds are exposed for a shorter time to high temperatures. Although drying with smaller pieces seem to be more beneficial, a (minimum) size is often prescribed, depending on the application of the food product. Typical examples are whole apple chips, which serve as healthy snacks, or the small apple cubes in cereals. Apart from the size, the shape of the fruit piece also plays a role in the drying kinetics.

Most studies on fruit drying choose a single size and shape for their investigation. This choice is based on the specific final product that is targeted, for example dried apple slices, and is quite case specific. There are some studies that look into the effect of fruit size or shape on the drying time or fruit quality. Both experimental techniques (Hansmann et al., 1998; Meisami-asl et al., 2010; Sabarez et al., 2012; Senadeera et al., 2003; van Nieuwenhuijzen et al., 2001; Zlatanović et al., 2013) and numerical modelling (Aversa et al., 2007; Curcio et al., 2016; Kaya et al., 2006; Kurnia et al., 2013; Lamnatou et al., 2010; Marra et al., 2010) have been used for this purpose. These studies only evaluate a few different sizes or shapes of fruit, or a few aspect ratios (Senadeera et al., 2003). As an alternative, analytical solutions are available which quantify the impact of the size on the transient convective scalar (heat or moisture) removal from the product (Datta, 2002). However, only information for very simple shapes is available (e.g. slab or spherical particles). For more complex-shaped products (flakes, sticks or irregularry shaped particles), empirical corrections are typically determined (Mujumdar, 2014). Previous studies which evaluated differences in size or shape also focused predominantly on the drying kinetics and not specifically on fruit quality evolution. A systematic evaluation on the impact of size and shape parameters on both the drying (residence) time and fruit quality is however not yet reported to the best knowledge of the author.

In this study, combined hygrothermal-quality modelling is used to investigate size and shape effects on the fruit drying kinetics, as well as on the associated quality loss of heat-sensitive compounds. Apple fruit is evaluated as it is a commonly-used system to study fruit drying, it is processed in different sizes and shapes, and it has a high commercial value. We evaluate different sizes (thicknesses) of following shapes: cube, rectangle with a square side surface, a circular slice and a half-circular slice. This study will aid drying technologists in choosing the optimal size and shape for their application, in order to guarantee a short drying time and a high quality, but which at the same time complies with product size/shape requirements. 


\section{Materials and methods}

\subsection{Continuum model for fruit tissue}

A continuum model was developed (Defraeye and Verboven, 2017) for calculating the heat and moisture transfer in fruit tissue during drying. Only the main characteristics are highlighted below. Important model assumptions are that evaporation is assumed to occur only at the fruit surface and that shrinkage of the fruit is not modelled. Such hygrothermal models, including these simplifications, are commonly used to evaluate drying processes, as detailed in a recent review of such models (Defraeye, 2014). The present numerical model was validated in a previous work with experimental data for drying kinetics and temperature (Defraeye and Verboven, 2017). Exactly these variables (drying rate and temperature, where the latter is linked to quality) are of interest in the present study.

\section{Conservation equations}

The following conservation equations for moisture and energy are solved to the dependent variables water potential $\psi$ $[\mathrm{Pa}]$ and temperature $T[\mathrm{~K}]$ :

$\frac{\partial w_{m}}{\partial \psi} \frac{\partial \psi}{\partial t}+\nabla \cdot\left(-K_{m} \nabla \psi\right)=0$

$h_{l} \frac{\partial w_{m}}{\partial \psi} \frac{\partial \psi}{\partial t}+\left(c_{p, s} w_{s}+c_{p, l} w_{m}\right) \frac{\partial T}{\partial t}+\nabla \cdot\left(-h_{l} K_{m} \nabla \psi\right)+\nabla \cdot\left(-\lambda_{P M} \nabla T\right)=0$

where $w_{s}$ and $w_{m}$ are the dry matter density (solid) and moisture content of the tissue $\left[\mathrm{kg} \mathrm{m}^{-3}\right]$, respectively. $K_{m}$ is the moisture permeability of the tissue $[\mathrm{s}], h_{l}$ is the enthalpy of liquid water $\left[\mathrm{J} \mathrm{kg}^{-1}\right], \lambda_{P M}$ is the thermal conductivity of the tissue (porous medium) $\left[\mathrm{W} \mathrm{m}^{-1} \mathrm{~K}^{-1}\right], c_{p, s}$ and $c_{p, l}$ are the specific heat capacities of dry matter and liquid water $\left[\mathrm{Jg}^{-1} \mathrm{~K}^{-1}\right]$, respectively. These material properties are detailed further in a previous study (Defraeye and Verboven, 2017). Note that $K_{m}$ equals $8 \times 10^{-16} \mathrm{~s}$ and the apple cultivar fruit is Braeburn.

\section{Boundary conditions}

The boundary conditions at the air-tissue interface are specified as:

$\mathbf{n} \cdot\left(-\mathrm{K}_{\mathrm{m}} \nabla \psi\right)=\mathrm{g}_{\mathrm{m}}=\mathrm{h}_{\mathrm{c}, \mathrm{m}}\left(\mathrm{p}_{\mathrm{v}, \mathrm{w}}-\mathrm{p}_{\mathrm{v}, \mathrm{ref}}\right)$

$\mathbf{n} \cdot\left(-\mathrm{h}_{\mathrm{l}} \mathrm{K}_{\mathrm{m}} \nabla \psi-\lambda_{\mathrm{PM}} \nabla \mathrm{T}\right)=\mathrm{g}_{\mathrm{T}}=\left(\mathrm{h}_{\mathrm{c}, \mathrm{T}}\left(\mathrm{T}_{\mathrm{w}}-\mathrm{T}_{\text {ref }}\right)-\mathrm{h}_{\mathrm{v}} \mathrm{g}_{\mathrm{m}}\right)$

where $g_{m}\left[\mathrm{~kg} \mathrm{~m}^{-2} \mathrm{~s}^{-1}\right]$ and $g_{T}\left[\mathrm{~J} \mathrm{~m}^{-2} \mathrm{~s}^{-1}\right]$ are the mass and heat fluxes at the interface, $\mathbf{n}$ is the unit vector normal to the interface, $h_{c, m}$ is the convective mass transfer coefficient (CMTC $\left.\left[\mathrm{s} \mathrm{m}^{-1}\right]\right), h_{c, T}$ is the convective heat transfer coefficient (CHTC $\left.\left[\mathrm{W} \mathrm{m}{ }^{-2} \mathrm{~K}^{-1}\right]\right), p_{v, w}$ and $p_{v, \text { ref }}$ are the vapor pressures at the interface and of the ambient air $[\mathrm{Pa}], T_{w}$ and $T_{\text {ref }}$ are the temperatures at the interface and of the ambient air [K], $h_{v}$ and $h_{l}$ are the enthalpies of water vapor and liquid water [J $\left.\mathrm{kg}^{-1}\right]$.

For heat transfer, the heat loss from the fruit, due to heat conduction and liquid water transport, equals the convective heat exchange with the surroundings and the heat removal due to the water vapor loss, including evaporation. For mass 
transfer, the moisture loss from the fruit equals the convective vapor removal from the surface. Long-wave radiation exchange of the fruit with the environment is not included in the model.

\subsection{Fruit quality modelling}

The change of a generic (heat-sensitive) quality parameter $A$ (e.g. enzymatic degradation, vitamin loss) during the drying process is calculated, as detailed in our previous work (Defraeye, 2016). To this end, a kinetic-rate-law model is built up to quantify the loss of this generic quality parameter (Robertson, 2016; Van Boekel, 2008):

$\frac{-d A}{d t}=k A^{n}$

where $k$ is the rate constant $\left[\mathrm{s}^{-1}\right], n$ is the order of the reaction which dictates to which extent the rate is dependent on the value of $A$, and $t$ is the time [s]. Zero-order reaction kinetics are assumed in this study. Examples of zero-order reactions are browning as a result of the Maillard reaction, lipid oxidation and enzymatic degradation (Robertson, 2016; Van Boekel, 2008). Using the same methodology also higher-order reactions can be modelled, such as first-order reactions (e.g. vitamin loss).

Solving this ordinary differential equation for a zero-order reaction thereby will result in a linear decrease of the quality parameter:

$$
A=A_{0}-k t
$$

where $A_{0}$ is the quality at the start of the drying process $(\mathrm{t}=0 \mathrm{~s})$ and the rate constant equals the slope of the linear curve. Note that for these reaction kinetic models, typically only the influence of temperature on the reaction rate is included (Robertson, 2016; Van Boekel, 2008). Note however that the impact of other parameters (e.g. light, oxygen concentration) can also be included in principle, but this is much less common. The main reason is that determining this multivariate dependency of a quality parameter is very time-consuming to determine. To include the dependency of quality decay to the temperature, the rate constant $k$ is made a function of temperature, for which typically an Arrhenius relationship is used:

$k(T)=k_{0} e^{\frac{-E_{A}}{R T}}$

where $k_{0}$ is a constant $\left[\mathrm{s}^{-1}\right], E_{A}$ is the activation energy $\left[\mathrm{J} \mathrm{mol}^{-1}\right], R$ is the ideal gas constant $\left(8.314 \mathrm{~J} \mathrm{~mol}^{-1} \mathrm{~K}^{-1}\right), T$ is the absolute temperature $[\mathrm{K}]$. To calculate $k(T), k_{0}$ and $E_{A}$ need to be known, which are calibrated based on information of the quality decay. The details of the calibration procedure are described in a previous work (Defraeye, 2016). Following assumptions are made to determine the quality parameters $E_{A}$ and $k_{0}$ for apple fruit: (1) $A_{0}\left(20^{\circ} \mathrm{C}, 0\right.$ hours $)=100 \%$; (2) $A_{\text {end }}\left(20^{\circ} \mathrm{C}, 100\right.$ hours $)=70 \%$, meaning that after the sample is kept 100 hours at $20^{\circ} \mathrm{C}, 30 \%$ of the quality parameter is assumed to be lost; (3) $Q_{10}=2$, meaning that an increase in temperature of $10^{\circ} \mathrm{C}$ doubles the rate constant $k$, so halves the time until all quality is lost. This $Q_{10}$ value equals the ratio of the rate constants at temperatures $T$ and $T+10 \mathrm{~K}$ $\left(=k_{T+10} / k_{T}\right)$ and is typically about 2-3 for degradation reactions in fruit (Robertson, 2016; Thompson, 2004). These assumptions result in an $E_{A}$ of $4.95 \times 10^{4} \mathrm{~J} \mathrm{~mol}^{-1}$ and a $k_{0}$ of $2.00 \times 10^{8} \% \mathrm{~h}^{-1}$ or $55.7 \times 10^{3} \% \mathrm{~s}^{-1}$. 


\subsection{Configuration and computational model}

Convective drying is evaluated for a piece of apple fruit suspended in the surrounding air. Drying of different fruit shapes is simulated (Figure 1):

- A cubic piece of length $L_{c u}$ and thickness $d_{c u}\left(=L_{c u}\right)$.

- A rectangular piece with a square side surface of length $L_{r}$ and with a thickness $d_{r}$.

- A circular slice with diameter $D_{c i}$ of $50 \mathrm{~mm}$, which is typical for the outer diameter of an entire apple fruit, and with a thickness $d_{c i}$.

- A half-circular slice with diameter $D_{c i}(50 \mathrm{~mm})$, and with a thickness $d_{c i}$.

Cube

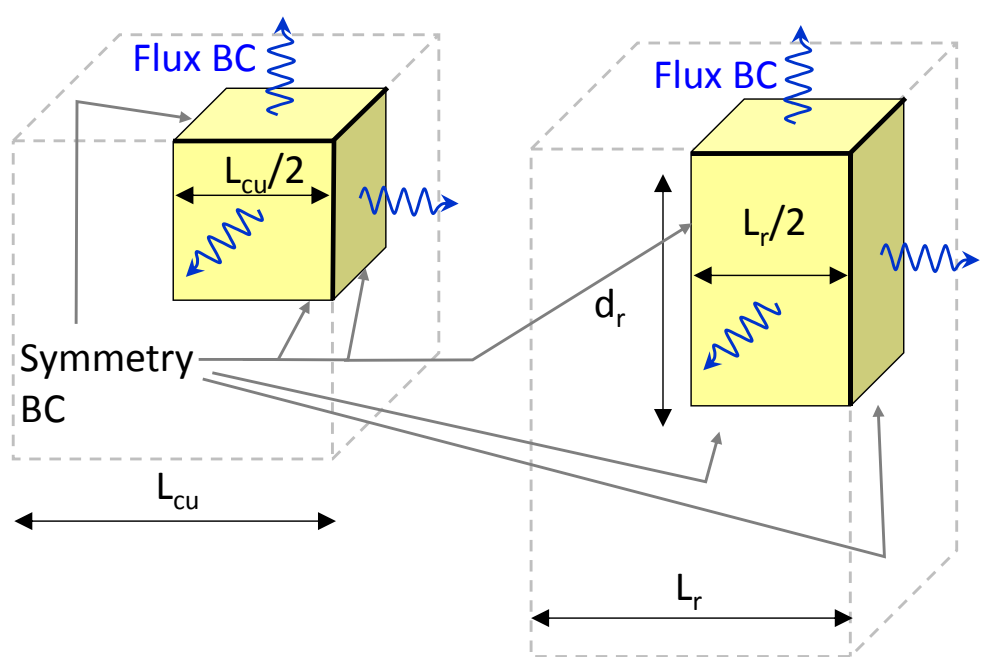

Full slice

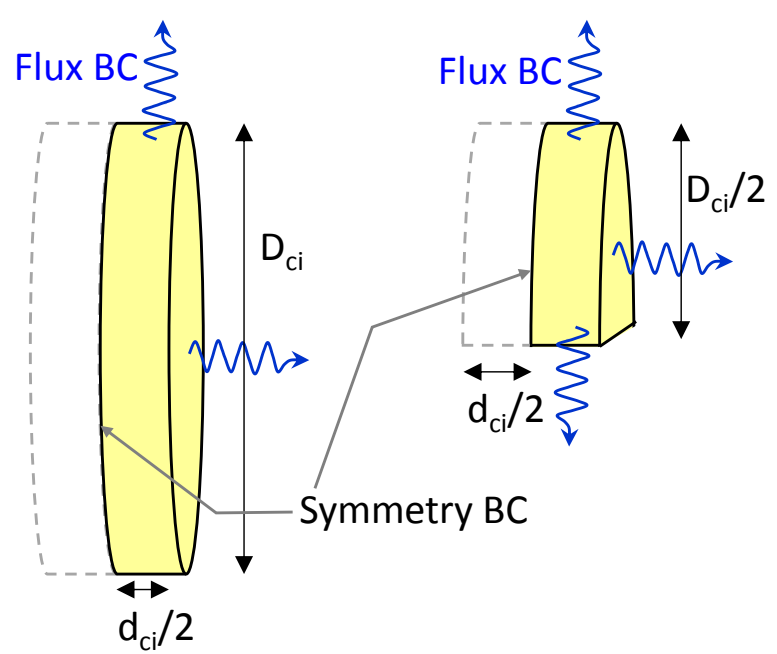

Figure 1. Computational model with boundary conditions. The grey dotted lines delineate the entire fruit geometry. Only the yellow colored parts are modelled due to symmetry.

These configurations were chosen based on the typical shapes in which apple fruit is processed by drying, namely cubes, sticks or circular slices. For each configuration, following thicknesses are calculated: 5, 10, 15, 20, 25, 30, 35, 40, 45, 50 $\mathrm{mm}$. A part of the ensemble of configurations that are evaluated is shown in Figure 2. For the cube, a change in thickness inherently implies that the other dimensions also change. For the rectangular case, also different $L_{r}$ are evaluated, namely 5, 10, 30 and $50 \mathrm{~mm}$. Thereby, a large parametric space is covered for the typical fruit sizes and shapes used in practice.

One additional configuration is evaluated, namely a rectangular slice with a thickness of $10 \mathrm{~mm}$ and a length $L_{r}=44.3$ $\mathrm{mm}$. The reason is that it will be compared to the circular slice $(10 \mathrm{~mm})$ and the half slice $(20 \mathrm{~mm})$, as these three samples have the same volume, so the same initial amount of water. 

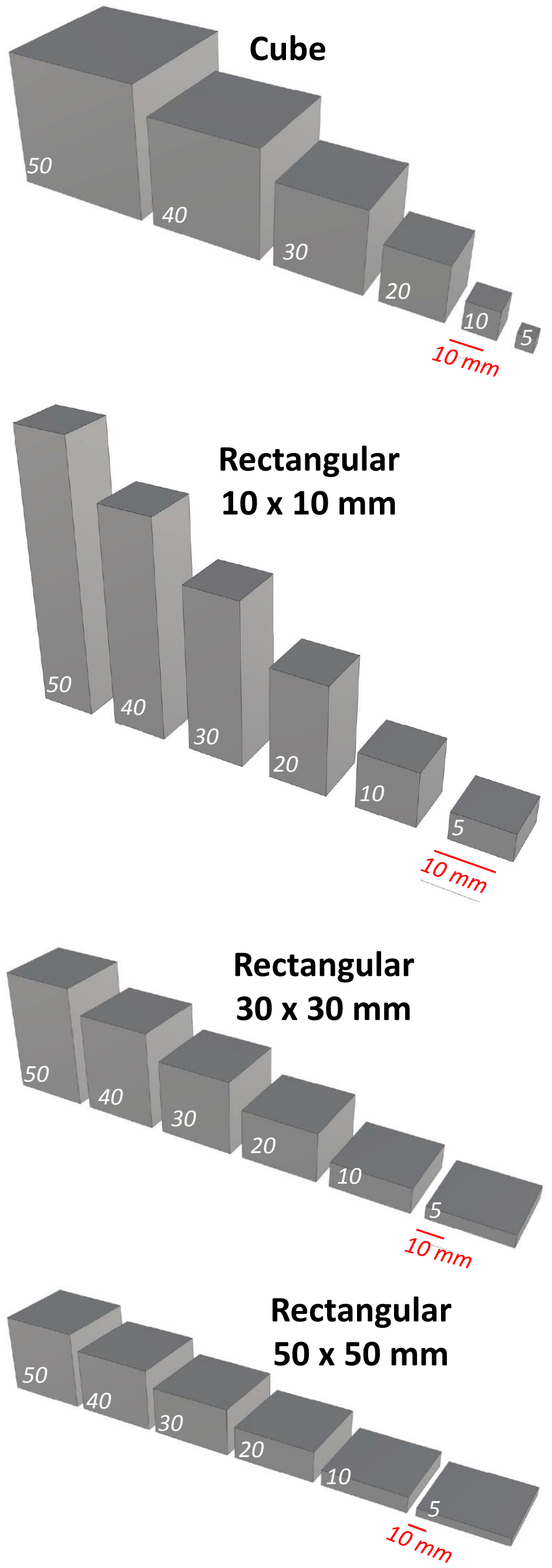
Figure 2. Illustration of a part of the configurations that are evaluated. A different scaling is applied between the different shapes.

The computational model and the imposed boundary conditions are specified in Figure 1. A 3D model of the fruit is used, but only a part of it is modelled due to symmetry, namely one eighth for the cube and rectangle, and half for the circular slices. The relevant boundary/initial conditions used for modelling are specified in Table 1 . The boundary conditions are typical for convective drying of fruit. Here the convective heat and mass fluxes at the surfaces are imposed. These are calculated from the convective transfer coefficients and the difference in temperature or vapor pressure between the fruit surface and the approach flow conditions.

As such, the airflow around the cube is not modelled explicitly, but its impact on the drying process is accounted for by using convective transfer coefficients (CTCs), which is often done for convective flow problems (Defraeye et al., 2012b). The same CTC value is assumed on all sides of the fruit. The CMTC is estimated from the CHTC using the heat and mass transfer analogy, similar as in our previous work (Defraeye et al., 2012a), leading to a ratio CMTC/CHTC (analogy factor) of $7.03 \times 10^{-9}$. The imposed drying conditions are typical for forced convective drying $\left(\mathrm{CHTC}=100 \mathrm{~W} / \mathrm{m}^{2} \mathrm{~K}\right)$ at elevated temperatures $\left(T_{\text {ref,d }}=40^{\circ} \mathrm{C}\right)$ with dry air $\left(R H_{r e f, d}=10 \%\right)$, similar to (Defraeye, 2016).

\section{Table 1. Boundary conditions and initial conditions.}

\begin{tabular}{|l|l|l|}
\hline Boundary and initial conditions & Symbol & Value \\
\hline Initial tissue temperature & $T_{\text {ini }}$ & $20\left[{ }^{\circ} \mathrm{C}\right]$ \\
\hline Initial tissue moisture content & $W_{m, \text { ini }}$ & $780\left[\mathrm{~kg} \mathrm{~m}^{-3}\right]$ \\
\hline Initial tissue moisture content (dry base) & $X_{\text {ini }}\left(=w_{m, i n i} / W_{s}\right)$ & $6\left[\mathrm{~kg} \mathrm{~kg}_{\mathrm{dm}}^{-1}\right]$ \\
\hline Drying air temperature & $T_{\text {ref }}$ & $40^{\circ} \mathrm{C}$ \\
\hline Drying relative humidity & $R H_{\text {ref }}$ & $10 \%$ \\
\hline Convective heat transfer coefficient & $h_{c, T}$ & $100\left[\mathrm{~W} \mathrm{~m}^{-2} \mathrm{~K}^{-1}\right]$ \\
\hline Convective mass transfer coefficient & $h_{c, m}$ & $7.03 \times 10^{-7}\left[\mathrm{~s} \mathrm{~m}^{-1}\right]$ \\
\hline
\end{tabular}

An appropriate grid is built for the porous material, based on a grid sensitivity analysis. A gradual refinement towards the air-tissue interface is applied to enhance numerical accuracy and stability as the largest gradients occur there at the start of the drying process. The grid size was also made dependent on the size of the sample. For the cube with $L_{c u}=10$ $\mathrm{mm}$, the grid consists of 27000 hexahedral finite elements for $1 / 8^{\text {th }}$ of the cube.

\subsection{Numerical simulations}

This hygrothermal-quality continuum model was implemented in COMSOL Multiphysics (version 5.2), which is a finiteelement based solver. The partial differential equations interface (coefficient form) was used, in which the hygrothermal conservation equations were implemented. The fruit quality model was solved using the ordinary differential equation solver. Starting from the specified initial conditions, transient simulations simulated a drying process of several hours, depending on the sample size. All simulations applied adaptive time stepping, as determined from a temporal sensitivity 
analysis. The tolerances for convergence and other solver settings were determined based on sensitivity analysis as well. A fully coupled solver was used to solve to the dependent variables $\psi$ and $T$.

\subsection{Comparing drying processes}

Since it is not straightforward to quantitatively compare differences in drying curves (mass loss versus time), an alternative way of evaluating the results is chosen. To this end, the critical drying time $\left(t_{c r i t}\right)$ is compared (Defraeye and Verboven, 2017). It is the time needed for the sample to reach the critical moisture content $\left(w_{\text {crit }}\right)$. The latter is defined as the (volume-)averaged moisture content in the sample that corresponds, via the sorption isotherm, to an equilibrium water activity below which no spoilage occurs $\left(a_{w, c r i t}\right)$. For dried fruit, this $a_{w, c r i t}$ is about 0.6 (Bonazzi and Dumoulin, 2011). In principle, if the drying process is stopped at $w_{\text {crit }}$ and the sample is equilibrated in an environment where the humidity corresponds to $a_{w, c r i t}$ or lower, the average final water activity in the tissue will be below $a_{w, c r i t}$. By stopping the process at $w_{\text {crit, }}$, the sample can be considered sufficiently dehydrated to avoid spoilage later on. Also over-drying is avoided that way, which could help save energy. For the present study, $w_{\text {crit }}$ was $37.8 \mathrm{~kg} \mathrm{~m}^{-3}$, leading to a dry matter moisture content $X_{\text {crit }}$ of $0.29 \mathrm{~kg} \mathrm{~kg} \mathrm{dm}^{-1}$. With $t_{\text {crit, }}$ only one characteristic value is obtained per drying curve, which facilitates quantifying differences between drying processes, instead of based on the entire drying curve. In addition to the drying time, the remaining fruit quality at $t_{\text {crit, }}$ namely $A_{\text {crit, }}$ is also used as a parameter to compare drying processes.

Comparing results of fruits of different shapes and sizes is not straightforward, as they have a different volume and surface area, and contain different amounts of water. To this end, the drying time and fruit quality will also be compared versus the initial amount of water in the sample $\left(=w_{m, \text { ini }} \times V_{f}\right)$ and versus the compactness (C) of the fruit slice. The compactness is defined as the ratio between the volume $\left(V_{f}\right)$ and the surface area exposed to the environment $\left(A_{f}\right)$. It can be calculated for the different shapes (cube: cu, rectangle: $r$, full circular: ci, half circular: hci):

$C_{c u}=\frac{V_{f}}{A_{f}}=\frac{L_{c u}^{3}}{6 L_{c u}^{c}}=\frac{L_{c u}}{6}$

$C_{r}=\frac{V_{f}}{A_{f}}=\frac{L_{r} L_{r} d_{r}}{2 L_{r}^{2}+4 L_{r} d_{r}}=\frac{L_{r} d_{r}}{2 L_{r}+4 d_{r}}$

$C_{c i}=\frac{V_{f}}{A_{f}}=\frac{\pi R_{c i}^{2} d_{c i}}{2 \pi R_{c i} d_{c i}+2 \pi R_{c i}^{2}}=\frac{R_{c i} d_{c i}}{2 d_{c i}+2 R_{c i}}$

$C_{h c i}=\frac{V_{f}}{A_{f}}=\frac{\frac{\pi R_{c i}^{2} d_{c i}}{2}}{\pi R_{c i} d_{c i}+2 R_{c i} d_{c i}+\pi R_{c i}^{2}}=\frac{\pi R_{c i} d_{c i}}{2\left(\pi d_{c i}+2 d_{c i}+\pi R_{c i}\right)}$ 


\section{Results}

\subsection{Drying time}

In Figure 3, the critical drying time is represented for different fruit shapes, as a function of the thickness of the sample. Three different representations are shown to enhance clarity, namely (a) the drying time, (b) the drying time on a log scale and, (c) the drying time, scaled with the value at the smallest thickness (for each geometry) on a log scale.

For the cube, the drying time increases rather quadratic with the cube thickness (thus length). This is in agreement with analytical solutions for convective scalar transfer from simple slab geometries. Here, the time to reach a certain average value of a scalar inside the slab (temperature, concentration) is proportional to the square of the characteristic dimension (Datta, 2002).

For the rectangular slices, the relation of the drying time to the thickness $\left(d_{r}\right)$ is more complex, which is induced by the varying aspect ratio, namely the ratio between $d_{r}$ and $L_{r}$. For small square surfaces, thus small $L_{r}$ (Rect. $5 \times 5 \mathrm{~mm}$ and Rect. $10 \times 10 \mathrm{~mm}$ ), the drying time reaches quite fast an almost constant value with increasing thickness. The reason is that the thickness $d_{r}$ becomes much larger than the other two dimensions $\left(L_{r}\right)$. As the aspect ratio is large, so representing a long beam such as a fruit stick (Figure 3b), drying occurs mainly in a two-dimensional way via the lateral surfaces. The impact of the edge effects on the drying time disappear almost completely for these slender geometries. The length of the rectangle $\left(L_{r}\right)$ can be considered now as the characteristic dimension for the drying process. As it does not change for a certain case (e.g. Rect. $5 \times 5 \mathrm{~mm}$ ), an increase in thickness $\left(d_{r}\right)$ does not lead to a significant increase in drying time. This means that fruit pieces with a large aspect ratio $\left(d_{r} \gg>>L_{r}\right)$ exhibit fast drying, with drying rates that are not so different from a cube with $L_{c u}=L_{r}$. Nevertheless, these sticks have a rather large volume of the dried piece $\left(d_{r} \times L_{r} \times L_{r}\right)$, compared to a cube of the same length, and contain less pieces per fruit batch. The (half-)circular slices dry very similar to some of the rectangular slices, as they have also very similar compactness as a function of the thickness (results not shown).
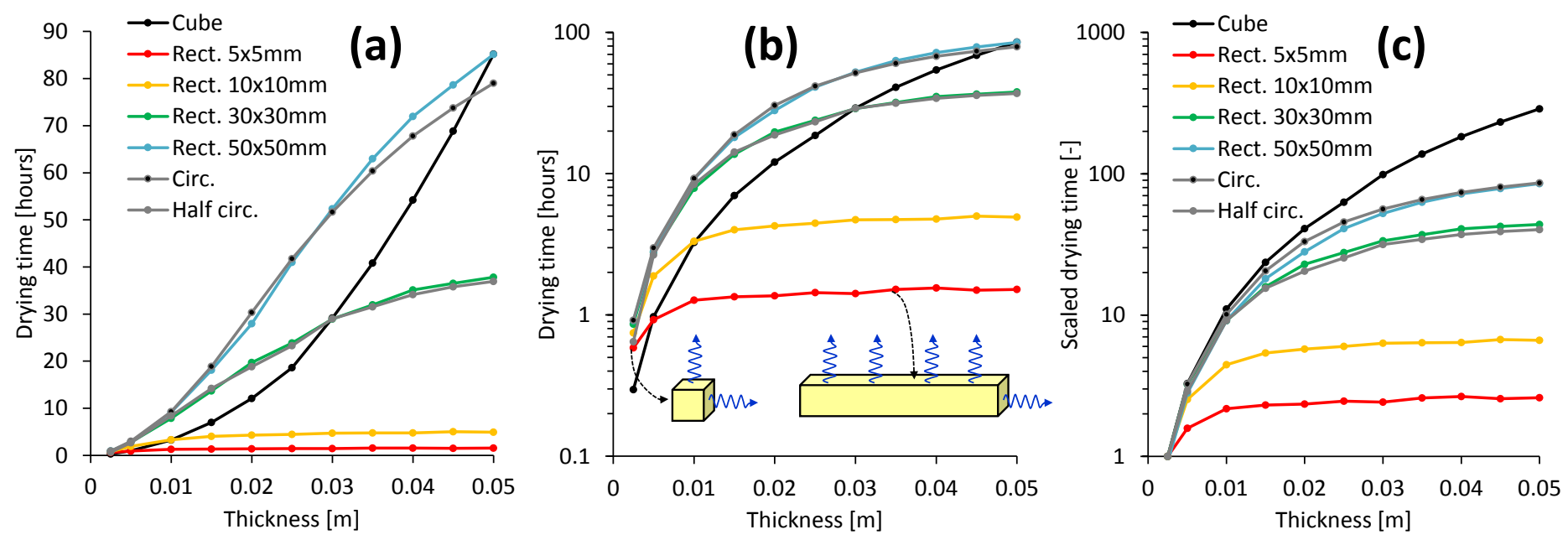

Figure 3. Critical drying time for different fruit slice shapes (Rect.: rectangular; Circ.: circular), as a function of the thickness of the sample: (a) drying time, (b) drying time on a log scale, (c) drying time scaled with the value at the smallest thickness (for each geometry) on a log scale. The legend is the same for all graphs. 
In Figure 4, the critical drying time is shown for different fruit shapes, as a function of (a-b) the compactness and (c) the initial mass of water in the sample (log-log scale) and (d) the initial mass of water in the sample scaled with the value at the smallest thickness for each geometry (log-log scale). Note that the initial mass $\left(w_{m, \text { ini }} \times V_{f}\right)$ is directly related to the fruit volume, as the $w_{m, \text { ini }}$ is taken equal for all samples. A quite general correlation is present $\left(R^{2}=0.985\right)$ between drying time and compactness $\left(=V_{f} / A_{f}\right)$ across the different fruit shapes and sizes, where more compact fruit (i.e. with $C$ $<<<$ ) clearly dry faster. Following correlation function is derived based on all data, as depicted in Figure 5 (all data points of Figure 4a):

$t_{\text {crit }}[$ hours $]=1.17 \times 10^{6} C^{2.02}$

Such correlations can help drying technologist to estimate the drying time of their product, for a certain fruit size or shape, based on its compactness. The compactness, which takes into account both volume and surface area is a good parameter to correlate drying time to fruit size and shape. No correlation is found between the initial mass of water in the fruit and the drying time, which is universally valid for different fruit shapes: the drying time for a certain initial water mass clearly differs based on the fruit shape. Note that the obtained correlations are valid for a given set of drying conditions $\left(R H_{\text {ref, }}, T_{\text {ref }}, U_{\text {ref }}\right)$. If the drying conditions change, the curves will also change.

When comparing the different geometries which have the same initial amount of water $\left(d_{r}=10 \mathrm{~mm} \& L_{r}=44.3 \mathrm{~mm}, d_{c i}\right.$ $=10 \mathrm{~mm}$ for circular slice, $d_{c i}=20 \mathrm{~mm}$ for half-circular slice), the half-circular slice dries the slowest $\left(t_{c r i t}=18.8 \mathrm{~h}\right)$, compared to the circular and rectangular slices, with a $t_{c r i t}$ of $9.3 \mathrm{~h}$ and $9.0 \mathrm{~h}$, respectively. This is directly correlated to the compactness, namely $C_{h c i}=4.3, C_{c i}=3.6, C_{r}=3.4$.
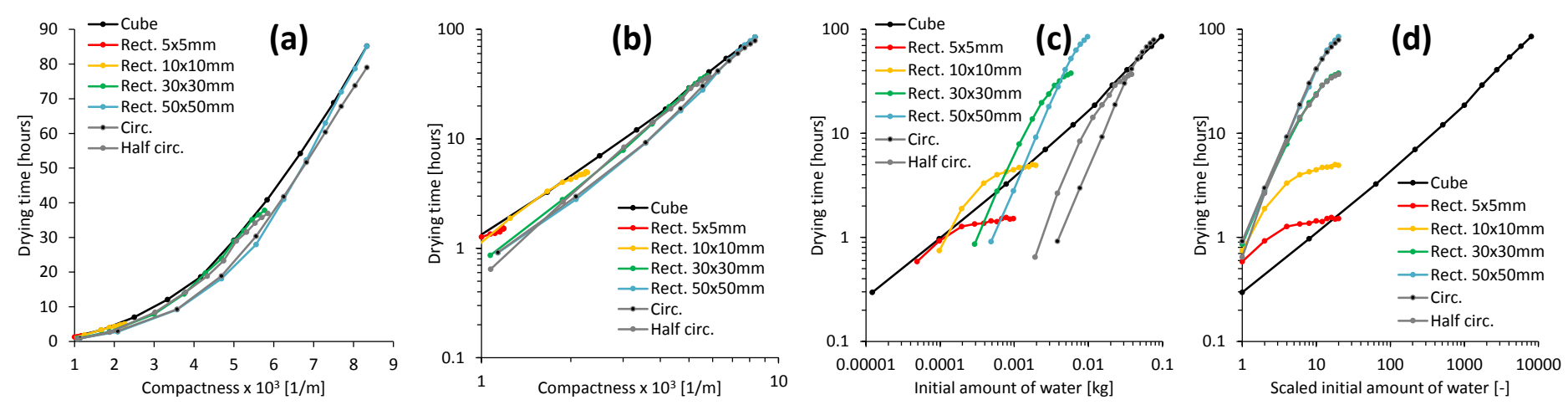

Figure 4. Critical drying time for different fruit slice shapes (Rect.: rectangular; Circ.: circular), as a function of (a-b) compactness (normal and log-log scale, compactness is scaled with a factor 1000), (c) the initial mass of water in the sample (log-log scale) and (c) the initial mass of water in the sample scaled with the value at the smallest thickness for each geometry (log-log scale). 


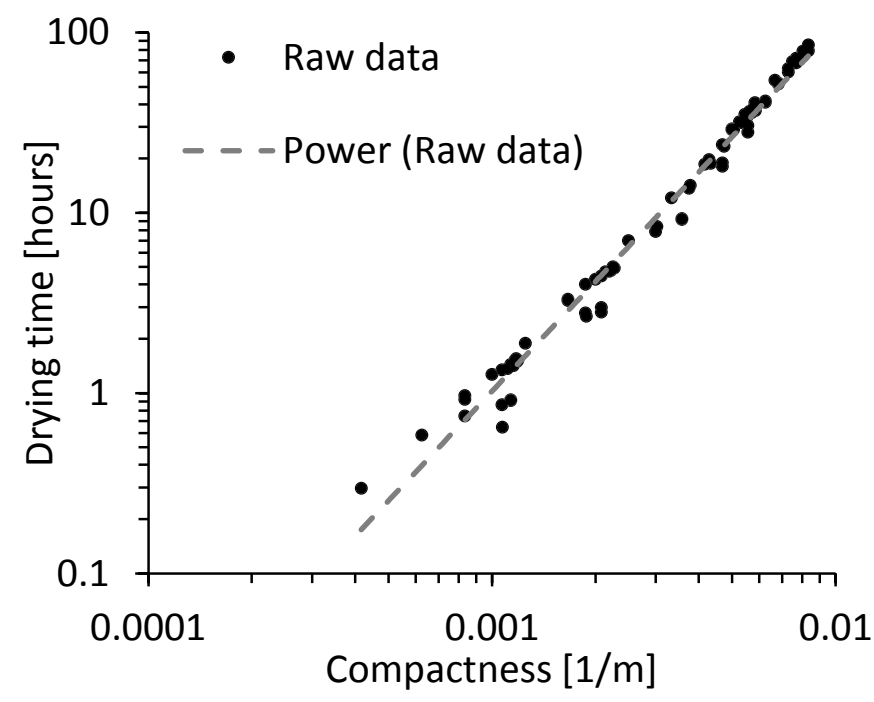

Figure 5. Raw data and corresponding correlation function of the critical drying time as a function of the compactness for all evaluated fruit slice shapes and sizes (log-log scale).

\subsection{Fruit quality}

In Figure 6, the critical fruit quality, namely $A_{\text {crit }}$ at time $t_{\text {crit, }}$, is shown for different fruit shapes, as a function of (a) the thickness of the sample, (b) the compactness and (c) the initial mass of water in the sample scaled with the value at the smallest thickness for each geometry (log scale). This critical fruit quality is thus the quality at the end of the drying process (time $\left.t_{c r i t}\right)$ so when the critical moisture content $\left(w_{c r i t}\right)$ is reached, meaning no spoilage is expected to occur. The final quality clearly depends on the size and shape of the fruit, where smaller samples retain a higher quality, since they take less time to dry. As with the drying time, a much better correlation of the quality loss with compactness is present than with the thickness or the initial amount of water. Note that a linear decrease of the quality with the drying time is considered by the zero-order kinetics model that is applied (Eq.(6)). Higher-order kinetics models, such as first-order kinetic model, can also easily be implemented in a similar way in the present hygrothermal-quality model.
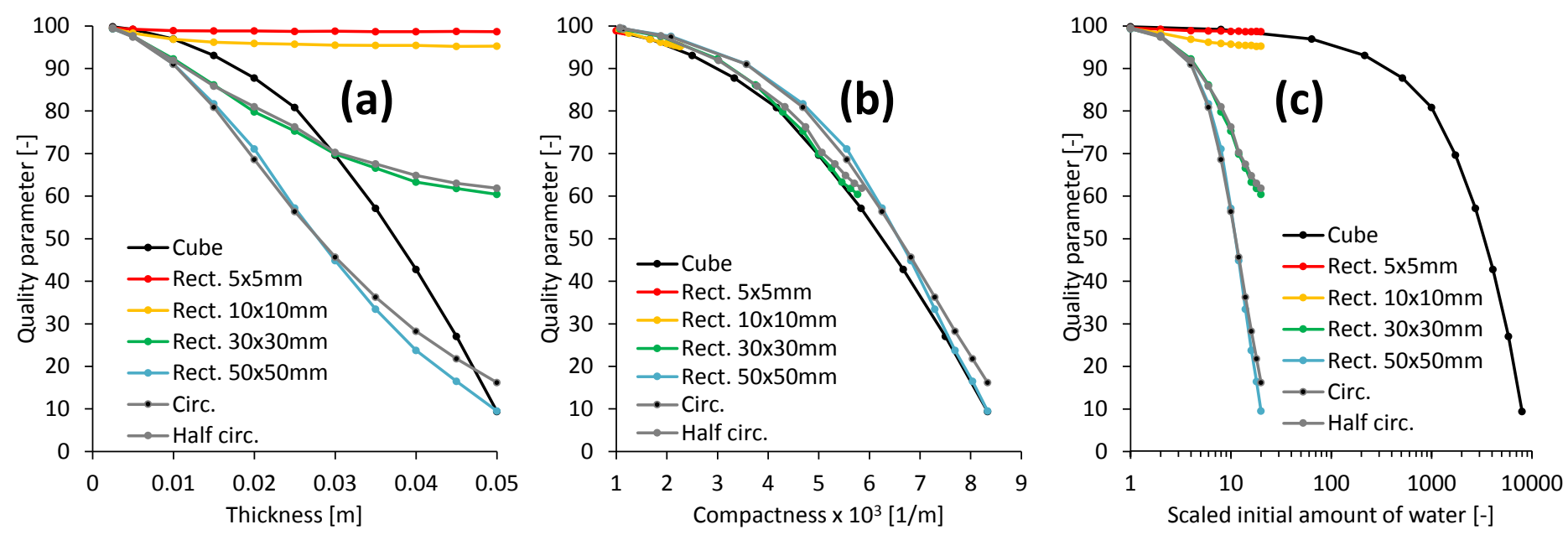
Figure 6. Critical fruit quality for different fruit slice shapes (Rect.: rectangular; Circ.: circular), as a function of (a) thickness of the sample, (b) compactness (scaled with a factor 1000), (c) the initial mass of water in the sample scaled with the value at the smallest thickness for each geometry (log scale). 


\section{Conclusions}

This study provides quantitative insight in the impact of different fruit sizes and shapes on both drying time and fruit quality evolution. As expected, smaller samples dry faster and retain quality better. However, for rectangular pieces with a square base surface $\left(L_{r} x L_{r}\right)$, pieces with a large aspect ratio $\left(d_{r} \gg \gg L_{r}\right)$ led to similar drying times as cubes with a similar base surface $\left(L_{c u} \approx L_{r}\right)$, although the latter had a much smaller volume. The reason is that drying occurs quasi twodimensional for these "fruit sticks" via the lateral surfaces. Hence increasing the width of the fruit slices $\left(d_{r}\right)$, can increase the volume of the fruit piece, and also reduces the amount of fruit pieces per batch, without compromising the drying time.

Furthermore, a good correlation across the different fruit shapes and sizes is found of both drying time and quality, with the compactness $\left(=V_{f} / A_{f}\right)$. More compact fruit, so with a lower volume to surface area ratio, clearly dry faster and retain quality better. The obtained correlations are helpful in estimating a-priori the drying time for a certain fruit size and shape. For fruit pieces with the same volume, so initial amount of water, the rectangular fruit dried the fastest, followed by the circular and half circular slice. This behavior could be directly related to the compactness. Note that the obtained correlation between compactness and drying time was derived in this study for specific drying conditions, so if other conditions are of interest, new correlations need to be determined.

This study provides insight on how fruit size and shape affect the drying process. By optimizing the residence time of the fruit in the dryer, energy savings and enhanced quality can be achieved. The hygrothermal-quality model can be easily extended or customized to different fruit species and quality attributes.

\section{Acknowledgements}

We acknowledge the support of the World Food System Center (WFSC) of ETH Zürich (www.worldfoodsystem.ethz.ch) and the support of the Swiss National Science Foundation SNSF (project 200021_160047).

\section{References}

Aversa, M., Curcio, S., Calabrò, V., lorio, G., 2007. An analysis of the transport phenomena occurring during food drying process. J. Food Eng. 78, 922-932. doi:10.1016/j.jfoodeng.2005.12.005

Bonazzi, C., Dumoulin, E., 2011. Quality changes in food materials as influenced by drying processes, in: Tsotsas, E., Mujumdar, A.S. (Eds.), Modern Drying Technology - Product Quality and Formulation. Wiley-VHC Verlag GmbH, Weinheim, Germany, pp. 1-20.

Curcio, S., Aversa, M., Chakraborty, S., Calabr??, V., lorio, G., 2016. Formulation of a 3D conjugated multiphase transport model to predict drying process behavior of irregular-shaped vegetables. J. Food Eng. 176, 36-55. doi:10.1016/j.jfoodeng.2015.11.020

Datta, A.K., 2002. Biological and Bioenvironmental Heat and Mass Transfer, 1st ed. New York. 
doi:10.1201/9780203910184

Defraeye, T., 2016. Towards more efficient intermittent drying of fruit: Insights from combined hygrothermal-quality modelling. Innov. Food Sci. Emerg. Technol. 38, 262-271. doi:10.1016/j.ifset.2016.10.003

Defraeye, T., 2014. Advanced computational modelling for drying processes - A review. Appl. Energy 131, 323-344. doi:10.1016/j.apenergy.2014.06.027

Defraeye, T., Blocken, B., Carmeliet, J., 2012a. Analysis of convective heat and mass transfer coefficients for convective drying of a porous flat plate by conjugate modelling. Int. J. Heat Mass Transf. 55, 112-124. doi:10.1016/j.ijheatmasstransfer.2011.08.047

Defraeye, T., Herremans, E., Verboven, P., Carmeliet, J., Nicolai, B., 2012b. Convective heat and mass exchange at surfaces of horticultural products: A microscale CFD modelling approach. Agric. For. Meteorol. 162-163, 71-84. doi:10.1016/j.agrformet.2012.04.010

Defraeye, T., Verboven, P., 2017. Convective drying of fruit: Role and impact of moisture transport properties in modelling. J. Food Eng. 193, 95-107. doi:10.1016/j.jfoodeng.2016.08.013

Hansmann, C.F., Joubert, E., Britz, T.J., 1998. Dehydration of peaches without sulphur dioxide. Dry. Technol. 16, 101121. doi:10.1080/07373939808917394

Kaya, A., Aydin, O., Dincer, I., 2006. Numerical modeling of heat and mass transfer during forced convection drying of rectangular moist objects. Int. J. Heat Mass Transf. 49, 3094-3103. doi:10.1016/j.ijheatmasstransfer.2006.01.043

Kurnia, J.C., Sasmito, A.P., Tong, W., Mujumdar, A.S., 2013. Energy-efficient thermal drying using impinging-jets with time-varying heat input - A computational study. J. Food Eng. 114, 269-277. doi:10.1016/j.jfoodeng.2012.08.029

Lamnatou, C., Papanicolaou, E., Belessiotis, V., Kyriakis, N., 2010. Finite-volume modelling of heat and mass transfer during convective drying of porous bodies - Non-conjugate and conjugate formulations involving the aerodynamic effects. Renew. Energy 35, 1391-1402. doi:10.1016/j.renene.2009.11.008

Marra, F., De Bonis, M.V., Ruocco, G., 2010. Combined microwaves and convection heating: A conjugate approach. J. Food Eng. 97, 31-39. doi:10.1016/j.jfoodeng.2009.09.012

Meisami-asl, E., Rafiee, S., Keyhani, A., Tabatabaeefar, A., 2010. Determination of suitable thin layer drying curve model for apple slices (variety-Golab). Plant Omics 3, 103-108. doi:10.1016/j.jfoodeng.2005.01.007

Mujumdar, A.S., 2014. Handbook of Industrial Drying, Fourth. ed. CRC Press, Taylor \& Francis Group, Boca Raton, USA. doi:10.1080/07373938808916399

Robertson, G.L., 2016. Food Packaging: Principles and Practice, Third Edition, Third. ed. Taylor \& Francis Group LLC, Boca-Raton. doi:10.1177/0340035206070163

Sabarez, H.T., Gallego-Juarez, J.A., Riera, E., 2012. Ultrasonic-Assisted Convective Drying of Apple Slices. Dry. Technol. 30, 989-997. doi:10.1080/07373937.2012.677083 
Senadeera, W., Bhandari, B.R., Young, G., Wijesinghe, B., 2003. Influence of shapes of selected vegetable materials on drying kinetics during fluidized bed drying. J. Food Eng. 58, 277-283. doi:10.1016/S0260-8774(02)00386-2

Thompson, J.F., 2004. Pre-cooling and storage facilities, in: USDA (Ed.), USDA Agriculture Handbook Number 66: The Commercial Storage of Fruits, Vegetables, and Florist and Nursery Stocks. USDA, pp. 1-10.

Van Boekel, M.A.J.S., 2008. Kinetic Modeling of Food Quality: A Critical Review. Compr. Rev. Food Sci. Food Saf. 7, 144158. doi:10.1111/j.1541-4337.2007.00036.x

van Nieuwenhuijzen, N.H., Zareifard, M.R., Ramaswamy, H.S., 2001. Osmotic drying kinetics of cylindrical apple slices of different sizes. Dry. Technol. 19, 525-545. doi:10.1081/DRT-100103932

Zlatanović, I., Komatina, M., Antonijević, D., 2013. Low-temperature convective drying of apple cubes. Appl. Therm. Eng. 53, 114-123. doi:10.1016/j.applthermaleng.2013.01.012 